Research Article

\title{
Surface Integrity of AISI 52100 Steel during Hard Turning in Different Near-Dry Environments
}

\author{
Ajay Chavan (i) and Vikas Sargade \\ Dr. Babasaheb Ambedkar Technological University, Lonere 402103, Raigad, Maharashtra, India \\ Correspondence should be addressed to Ajay Chavan; ajaychavan@dbatu.ac.in
}

Received 23 February 2020; Accepted 27 July 2020; Published 24 August 2020

Academic Editor: Victor M. Castaño

Copyright (c) 2020 Ajay Chavan and Vikas Sargade. This is an open access article distributed under the Creative Commons Attribution License, which permits unrestricted use, distribution, and reproduction in any medium, provided the original work is properly cited.

\begin{abstract}
AISI 52100 hardened bearing steel is popular in many industrial applications due to its excellent wear resistance and high strength. Therefore, a high level of surface integrity of the same is the utmost important requirement to enhance fatigue life. Machining of hardened AISI 52100 steel is difficult because severe plastic deformation and generation of high temperature alter the surface metallurgy of the machined component and hamper the tool life. The present investigation includes a comparative analysis of surface integrity of AISI 52100 bearing steel during hard turning under different near-dry environments, namely, dry, Minimum Quantity Cooling and Lubrication (MQCL), Compressed Chilled Air by Vortex Tube (CCAVT), and Hybrid Nanofluid Minimum Quantity Cooling and Lubrication (Hybrid NF-MQCL). Soyabean (a vegetable) oil is used as cutting fluid in MQCL and base fluid in Hybrid NF-MQCL environments. To prepare hybrid nanofluid, two different nanoparticles $\mathrm{Al}_{2} \mathrm{O}_{3}$ and MWCNT, are used. The chilled air is generated through a vortex tube. The surface integrity of AISI 52100 steel was studied in terms of microhardness, the thickness of the white layer, surface roughness $\left(R_{\mathrm{a}}\right)$, and residual stresses. Higher cutting speed and feed show positive and negative correlation on surface integrity of AISI 52100 steel, respectively. Hybrid nanofluid MQCL exhibits the lowest surface roughness $(0.34 \mu \mathrm{m})$, microhardness $\left(625 \mathrm{Hv}_{0.1}\right)$, compressive residual stresses $(-168 \mathrm{MPa})$, and thin white layer $(0.9 \mu \mathrm{m})$ in contrast, and dry machining shows higher surface roughness, microhardness, tensile residual stress, and thick white layer. In comparison, MQCL and CCAVT are found to be intermediate. It is found that hybrid nanofluid MQCL enhances the overall performance of the machined surface as compared to other near-dry techniques.
\end{abstract}

\section{Introduction}

AISI 52100 is a high quality bearing steel alloy. It is a solution treated hardened low alloy steel, which contains high carbon, chromium, and manganese. The hardness is in the range of 55 to $60 \mathrm{HRC}$. It shows light tempered martensite, less amount of retained austenite, and primary carbides in the microstructure after hardening. Hence, it exhibits improved mechanical properties such as tensile strength, yield strength, high bulk, and shear modulus properties [1]. AISI 52100 steel poses excellent wear resistance against dynamic loading; therefore, it is extensively used in valve bodies, pumps and fittings, transmission shafts, locomotives, machine tools, tractors, and mining machinery components [2].

However, many industrial applications such as bearing, gauges, and dead centers require a hardened AISI 52100 to improve their wear resistance. The conventional manufacturing processes of these components are the preparation of blanks using forging or casting, annealing to relieve stresses, rough machining, finish machining, hardening, and finish grinding. These processes require a long processing time resulting in a reduction of productivity and degraded product quality. Thus, hard turning with a potential benefit such as shorter setup time, high flexibility, and ability to handle complex geometry is an alternative machining process that replaces the finish machining and finish grinding step for machining of AISI 52100 steel [3].

However, hard turning has different challenges in machining, which are high cutting forces, rapid tool wear, and high cutting zone temperature, which lead to unacceptable surface integrity $[4,5]$. The surface integrity of the machined components plays a vital role in its functional performance 
and service life. It is measured in terms of white and dark layers, microstructure alteration, surface roughness, residual stresses, and microhardness [6].

Zhang et al. [7] investigated the mechanism of forming white layer and dark layer in hard machining AISI 52100 steel. They observed that rapid change in the austenite phase with a quenching effect due to the combined effect of plastic deformation and phase transformations produces a white layer after machining. However, the dark layer was a result of the combined effect of plastic deformation and high temperature on the tempering process. In another study, Zhang et al. [8] examined the effect of flank wear and cutting speed on residual stresses and microstructure of white and dark layers in the hard cutting of AISI 52100 steel using PCBN (Polycrystalline Cubic Boron Nitride) tool. They found compressive residual stresses in the white layer at low cutting speed, compared to tensile residual stresses in the white layer at high cutting speed. Chaudhari et al. [9] discussed the effect of flank wear on the formation of residual stresses in hard machining of hardened steels, namely, AISI 4319 and AISI 52100. They encountered the occurrence of higher tensile residual stress with the progression of tool flank wear, which indicates increased heat generation at the work tool interface due to an increase in work tool contact length. While the new cutting edge indicates compressive residual stress due to low heat generation. Jomaa et al. [10] discussed the enhancement of machining induced residual stresses and microstructure of hardened AISI 4340 steel by induction hardening. They concluded that cutting conditions affect residual stresses distribution; i.e., higher cutting speed $(202 \mathrm{~m} / \mathrm{min})$ causes tensile residual stresses on the surface. The machinability assessment of coated and uncoated carbide inserted in hard turning of AISI D2 steel was compared by Kumar et al. [11]. The (TiN-TiCN- $\mathrm{Al}_{2} \mathrm{O}_{3}$ ) coated carbide tool performed best as compared to the uncoated tool due to the thermal barrier property of $\mathrm{Al}_{2} \mathrm{O}_{3}$ and diffusion barrier lubricating property of TiN coating. Sahoo [12] analyzed the surface roughness results of hardened AISI D2 steel in hard turning using a coated carbide tool. He found lowered surface roughness at higher cutting speed, and this is due to the disappearance of BUE formation and the decrease in chip-tool contact length at higher cutting speed. In another study, Sahoo et al. [13] investigated flank wear of PVD TiN coated mixed ceramic insert in hardened steel turning. They observed abrasion and diffusion wear mechanism on flank face at higher cutting speed and feed. Panda et al. [14] evaluated machinability characteristic surface roughness, tool wear, and chip morphology in hard turning of AISI 52100 steel by multilayered coated carbide tool. They noticed a sharp rise in surface roughness quality in higher feed rate range, which is due to induced vibration in hard turning process.

However, in dry hard turning of AISI 52100 steel, a high machining temperature is generated at the chip-tool and tool-workpiece interface, which affects the surface integrity. This high-temperature generation in the machining zone is controlled by applying effective cooling and lubrication. The conventional flood cooling suffers from drawbacks like high processing cost, pollution due to disposal issues, and hazardous fumes to operators. These issues of flood cooling compel us to use advanced near-dry machining techniques, such as MQL [2], nanofluid MQL [15], and compressed air [16].

However, Bicek et al. [17] compared the machinability of hardened and normalized AISI 52100 steel in dry, flood, and cryogenic cooling conditions using the CBN cutting tool. It was reported that cryogenic cooling shows less white layer thickness with lower microhardness variation in comparison with dry and flood cooling. Umbrello et al. [18] studied the effect of cryogenic cooling on white layer thickness, grain size, residual stresses, surface roughness, and phase transformation in hard turning of AISI 52100 steel using the CBN tool. They found that cryogenic cooling limits the formation of the white layer and favors the generation of compressive residual stresses in all conditions. Sredanovie et al. [19] investigated hard machining of AISI 52100 steel using a PVD coated carbide tool under high jet pressure cooling. The high jet pressure coolant penetrates deeper and is more focused in the cutting zone, reduces friction, and evacuates chip easily. Hence, they found improvement in tool life and surface roughness in high jet pressure cooling in comparison with the dry cutting environment. Chinchanikar et al. [20] studied the effect of different machining environments on surface roughness produced in turning of hardened AISI 52100 steel. They found that the lower surface roughness was observed at higher cutting speeds for the coconut oil MQL machining environment due to low friction and low tool wear. Leppert et al. [21] studied the induced residual stresses in turning of AISI 316L steel under dry and MQL environment. The higher tensile residual stresses were observed in the circumferential direction than the axial direction for all environments. MQL environment exhibited lower tensile residual stresses at moderate and higher feed for all cutting speeds.

However, to improve the performance of the process, the role of machining the environment is prominent. From the above studies, it is indicated that more work is carried out by using a super abrasive tool like PCBN, $\mathrm{CBN}$, and ceramic tools. However, low cost, good quality, and updated PVD coated carbide tools are very less discussed. It is also found that there is a lack of knowledge about the significance of near-dry machining environments like CCAVT, MQCL, and Hybrid NF-MQCL on surface integrity. CCAVT is a very effective near-dry technique to use. It consists of only a vortex tube that is operated on compressed air and provides chilled air. Moreover, no experimental study has been reported for the effect of CCAVT, and Hybrid NF-MQCL on surface integrity of harden AISI 52100 bearing steel. Therefore, the present study mainly focuses on improving the machined surface-quality using different cutting environments like dry, CCAVT, MQCL, and Hybrid NF-MQCL in relation to cutting speed and feed. Also, the surface integrity attributes, namely, white layer formation, microhardness, residual stresses, and surface roughness, are investigated in hard turning of AISI 52100 steel using coated carbide tool. The detailed experimental theme is shown in Figure 1. 


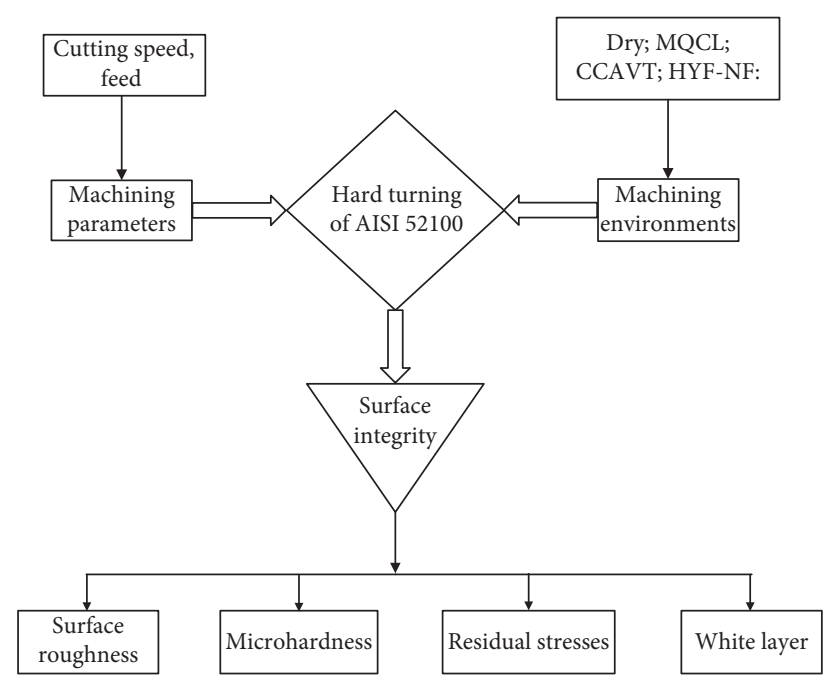

FIgURE 1: Experimental theme.

\section{Materials and Methods}

In this study, AISI 52100 bearing steel was used as workpiece material; its chemical composition is reported in Table 1 . The AISI 52100 steel cylindrical rods of $\varnothing 80 \mathrm{~mm}$ and $230 \mathrm{~mm}$ long were selected. All rods were austenitized, quenched, and tempered to maintain the average hardness of $55 \pm 3$ HRC.

A commercially available PVD coated multilayered TiSiN/TiAlN tungsten carbide inserts (Seco make TH1000 Grade) were used in this study. It has a rhombus shape with $80^{\circ}$ negative geometries and a $0.8 \mathrm{~mm}$ nose radius. This tool inserts with ISO designated geometry CNMG 120408-MF5 were mounted on tool holder PCLNL 2525-M12. All turning tests were performed on CNC lathe (ACE-JOBBER XL). A set of five consecutive cuts in the same position of each $30 \mathrm{~mm}$ cutting length was set for each turning trial. Experiments were performed under different near-dry machining environments, namely, dry, CCAVT, MQCL, and Hybrid NF-MQCL. In this study, experiments were designed using a general full factorial method, with an $\mathrm{L}_{9}$ array $\left(3^{2}\right)$ for each machining environment. The selected process parameters and their levels, constant parameters, and response parameters are listed in Table 2. The cutting parameters were selected based on cutting tool manufacturer's data, past literature, and preliminary experiments.

Two experimental setups were designed for CCAVT, and MQCL and Hybrid NF-MQCL machining environments, as shown in Figures 2 and 3. Figure 2 shows the CCAVT environment experimental setup of which vortex tube (Nex Flow $^{\mathrm{TM}}$ Frigid- $\mathrm{X}^{\mathrm{TM}}$ ) was used. It is a spot cooling system that produces chilled air in the range of $5^{\circ} \mathrm{C}-10^{\circ} \mathrm{C}$. The vortex tube was mounted on the top of the turret using a magnetic fixture. The cold outlet nozzle of the vortex tube was directed towards the rake face of the tool. The flexible hosepipe is used to connect inlet with the compressor.

The second experimental setup consists of the Noga Mini Cool MC3000 MQL system, which was used in MQCL and Hybrid NF-MQCL machining environments, as shown in
Figure 3. The MQL system produced mist spray of cutting fluid in minimum quantity. The MQL system was mounted on top of the turret using a magnetic fixture. The outlet nozzle of mist oil was directed towards the tool rake face. The oil inlets were dipped in the oil/hybrid nanofluid reservoir, and the air inlet was attached to the compressor using a flexible hosepipe. Soybean oil was used as cutting fluid in the MQCL machining environment, whereas hybrid nanofluid was used in the case of a Hybrid NF-MQCL machining environment. The flow rate of cutting fluid, for soybean oil in MQCL and hybrid nanofluid in Hybrid NF-MQCL, was maintained at $100 \mathrm{ml} / \mathrm{hr}$.

The hybrid nanofluid was prepared using the two-step method. Initially, a mixture of $\mathrm{Al}_{2} \mathrm{O}_{3}$ nanoparticles (size 50-70 nm) and multiwall carbon nanotube (MWCNT) particles (size $40-60 \mathrm{~nm}$ ) was added in $100 \mathrm{ml}$ of soybean oil and ultrasonication for 4 hours were carried out. Then to maintain the stability of nanofluid, a gum-Arabic surfactant was added and sonicated for 1 hour. The weight percentages of nanoparticles in nanofluid were $0.5 \%$ MWCNT and $1 \%$ $\mathrm{Al}_{2} \mathrm{O}_{3}$, of $100 \mathrm{ml}$ of soybean oil. The surfactant is also added in a weight percentage of $10 \%$ of nanoparticles calculated weight.

The surface integrity of the machined surface was analyzed through surface roughness, microhardness, residual stresses, and white layer thickness. But microhardness, residual stresses, and white layer thickness are measured in high cutting parameters (Vc: $200 \mathrm{~m} / \mathrm{min}$ and f: $0.2 \mathrm{~mm} / \mathrm{rev}$ ) to analyze the effect of cooling and lubrication of the above considered near-dry machining environment on it. Besides, after each experiment, the tool condition was observed in each cutting environment under the Tool Maker microscope (TM-505). The surface roughness of the machined component was measured using surface roughness tester (Mitutoyo: SJ 301) with a cut-off length of $0.8 \mathrm{~mm}$ after each experiment. Samples of $10 \times 10 \times 6 \mathrm{~mm}$ size were cut using wire EDM (see Figure 4) to measure microhardness, residual stresses, and thickness of the white layer of the machined surface. The samples were mounted and polished by using the standard procedure to measure microhardness. Additionally, the etching by nital (a mixture of 2-3 $\mathrm{ml}$ nitric acid in $100 \mathrm{ml}$ alcohol) etchant for $10 \mathrm{~s}$ is carried out to analyze white layer formation. The analysis of the white layer was performed on an FEI Quanta 200 scanning electron microscope.

The microhardness was measured at the machined surface, and its beneath, up to $350 \mu \mathrm{m}$ with $50 \mu \mathrm{m}$ of the interval, on Vickers microhardness tester (Matsuzawa $\mathrm{MTH}$ ). The average of three indentations is considered, which was measured in a lateral direction with a spacing of $40 \mu \mathrm{m}$, as shown in Figure 4 . A load of $0.1 \mathrm{~kg}$ was applied for $10 \mathrm{~s}$ for all the indentations. The residual stresses of the machined surface were analyzed using X-ray diffraction (XRD) analysis on the Panalytical diffractometer (Model: $\mathrm{X}^{\prime}$ Pert Pro, X-ray tube with $\mathrm{Cu}$ target with the wavelength of $1.54184 \AA$ A , X-ray generator: $40 \mathrm{kV} \& 30 \mathrm{~mA} / 45 \mathrm{kV} \& 40 \mathrm{~mA}$ ). Figure 4 shows the sample size and its preparation for the measurement of residual stress. The circumferential residual stresses parallel to the cutting direction were considered for 
TABLE 1: Chemical composition of AISI 52100 steel.

\begin{tabular}{lcccccc}
\hline $\mathrm{Fe}$ & $\mathrm{C}$ & $\mathrm{Si}$ & $\mathrm{Cr}$ & $\mathrm{S}$ & $\mathrm{Mn}$ & \\
\hline 96.89 & 1.01 & 0.22 & 1.41 & 0.05 & 0.4 & \\
\hline
\end{tabular}

TABLE 2: Experimental parameters.

\begin{tabular}{|c|c|}
\hline Constant parameters & \\
\hline Workpiece material & AISI 52100 bearing steel $(55 \pm 3 \mathrm{HRc})$ \\
\hline Cutting insert & PVD coated TiSiN-TiAlN WC (SECO TH1000) \\
\hline Depth of cut (mm) & 0.30 \\
\hline Flow rate in MQL $(\mathrm{ml} / \mathrm{hr}$.) & 100 (at $0.5 \mathrm{MPa}$ air pressure) \\
\hline Nozzle stand of distance $(\mathrm{mm})$ & 20 \\
\hline Base oil for MQCL & Soybean (vegetable oil) \\
\hline Nanoparticles for nanofluid & $\begin{array}{l}\text { (1) MWCNT:(length: } 10 \mu \mathrm{m} \text {, outer diameter: } 15 \mathrm{~nm} \text {, bulk density: } 0.04-0.06 \mathrm{~g} / \mathrm{cm}^{3} \text { ) } \\
\text { (2) } \mathrm{Al}_{2} \mathrm{O}_{3}: \text { (particle size: } 60 \mathrm{~nm} \text {, density: } 3.95 \mathrm{gm} / \mathrm{ml}^{3} \text { ) }\end{array}$ \\
\hline \multicolumn{2}{|l|}{ Variables } \\
\hline Cutting speed (m/min) & 80,140 , and 200 \\
\hline Feed $(\mathrm{mm} / \mathrm{rev})$ & $0.08,0.14$, and 0.2 \\
\hline Machining environment & (a) Dry, (b) CCAVT, (c) MQCL, and (d) Hybrid NF-MQCL \\
\hline \multicolumn{2}{|l|}{ Responses } \\
\hline Surface integrity & a) White layer formation, residual stresses $(\mathrm{MPa})$, microhardness $(\mathrm{Hv})$, and surface roughness $(\mu \mathrm{m})$ \\
\hline
\end{tabular}

the analysis, as shown in Figure 4. After that, a prepared sample was mounted on an X-ray diffractometer for biaxial residual stress measurement. The $\sin ^{2} \psi$ method was used to measure the residual stress of machined surfaces. The properties used for the calculation were Poisson's ratio of 0.27 and Young's modulus of $201 \mathrm{GPa}$ [1]. The $\mathrm{Cu}-\mathrm{K} \alpha$ was used as a source for residual stress measurement, along with a $(2,2,0)$ plane, and a diffraction angle $(2 \theta)$ of $135^{\circ}$ was considered.

\section{Results and Discussion}

3.1. Surface Roughness. Figure 5 reported the surface roughness $\left(R_{\mathrm{a}}\right)$ values for different cutting environments. It is observed that surface roughness is directly proportional to feed. The highest $R_{\mathrm{a}}$ value of $2.4 \mu \mathrm{m}$ was found in the dry machining environment, whereas the lowest value of $1.2 \mu \mathrm{m}$ was obtained in Hybrid NF-MQCL for feed $0.2 \mathrm{~mm} / \mathrm{rev}$. The Hybrid NF-MQCL environment exhibits lower surface roughness as compared to the other cutting environments, as can be seen from Figure 5. The $\mathrm{Al}_{2} \mathrm{O}_{3}$ enriched nanofluid is popular in MQCL machining due to its ball-bearing effect, which reduces the coefficient of friction between sliding contact surfaces [22]. The MWCNT nanoparticle enhances thermal conductivity as well as the fluidity of base fluid [23]. The hybridization of $\mathrm{Al}_{2} \mathrm{O}_{3}$ and MWCNT nanoparticle enhances thermal connectivity, fluidity, and lubrication properties of base fluid [24, 25].

This combination of MWCNT and $\mathrm{Al}_{2} \mathrm{O}_{3}$ nanoparticles in a base oil produces the billions of nanosized quasispherical rolling elements, which possess a porous sheet structure on tool and workpiece [23, 24, 26]. Hence, the Hybrid NF-MQCL possesses the lowest coefficient of friction in between work tool and tool-chip than other environments. Therefore, it reduces tool flank wear effectively and gives a better surface finish; it is shown in Figure 6(d). However, in the case of dry turning, there is direct contact of tool and workpiece, which causes more severe wear (see Figure 6(a)). Also, this high friction causes the generation of high heat generation, which results in a high-temperature rise in the cutting zone. This high heat generation tool may change its shape, which results in an increase in surface roughness in case of a dry environment. Surface roughness values observed in the case of MQCL and CCAVT are higher than the Hybrid NF-MQCL and lower than the dry environment. However, $R_{\mathrm{a}}$ value for CCAVT is higher than that for MQCL. This is because CCAVT provides only cooling effect (due to forced convection) by supplying chilled air. The MQCL system exhibits cooling (due to evaporation mechanism) as well as lubrication (injection method) phenomenon through base oil [27], which results in less tool wear.

The surface roughness decreased with an increase in cutting speed. This phenomenon occurs because at higher cutting speed, the cutting zone temperature rises which leads to thermal softening of material [21]. Besides, with increasing the cutting speed, the time available for the chip to stick to the tool decreases. This results in less tendency for built-up edge formation, and hence the lowered surface roughness was observed.

However, the surface topography plays an essential role in primary estimation for the functional life of the components. The surface roughness values obtained in different machining environments (Figures 5(a)-5(c)) is evidenced by surface topography analysis of machined surface through SEM images (Figures $7(\mathrm{a})-7(\mathrm{~d})$ ) obtained in the respective machining environments at Vc: $200 \mathrm{~m} / \mathrm{min}$ and $\mathrm{f}: 0.2 \mathrm{~mm} /$ rev. However, Figure 7 (a) reveals highly rough surface topography for dry machining. This indicates that surface topography observed under dry machining environment shows the feed marks, side flow, debris particles, and cracks on the machined surface. It results in increased surface roughness. However, Figures 7(b) and 7(c) show the machined surface topography observed under MQCL and 

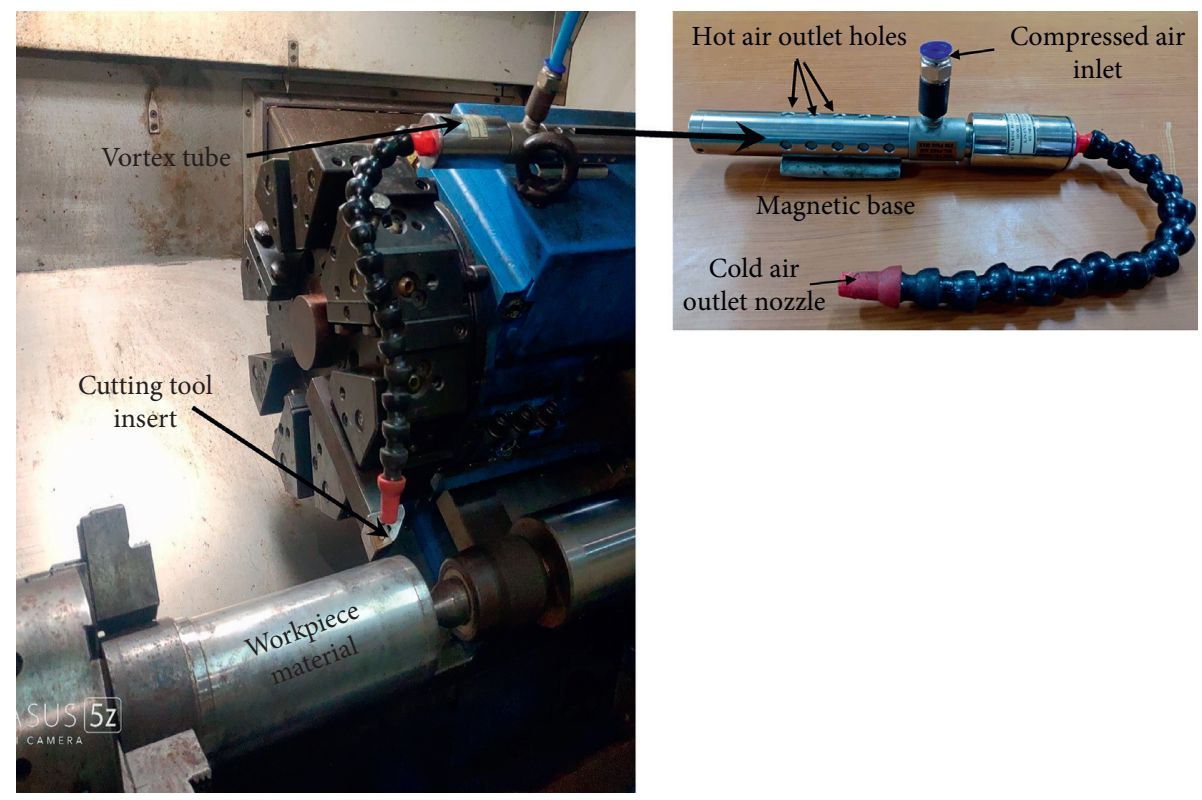

Figure 2: Experimental setup of Compressed Chilled Air by Vortex Tube.

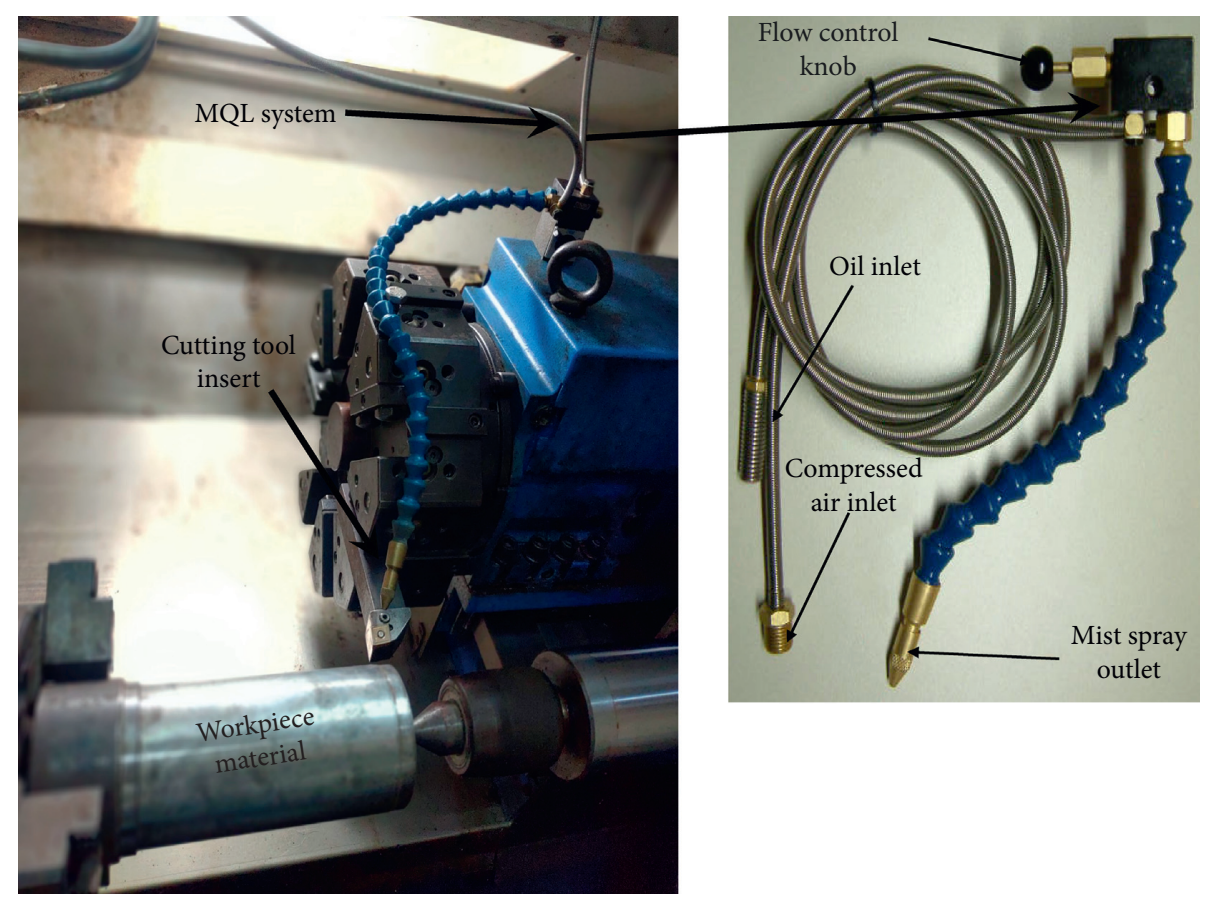

FIgURE 3: Experimental setup of Hybrid NF-MQCL/MQCL Setup.

CCVT machining environment process. The feed marks were found in these surfaces due to tool path movement, whereas the high temp effect gives out cracks, side flows, and debris particles. Figure $7(\mathrm{~d})$ indicates surface topography under hybrid NF-MQCL, which shows only feed marks and small cracks.

3.2. Microhardness. The microhardness values of the machined surface and subsurface, for all near-dry cutting environments, are shown in Figure 8. Microhardness of the machined surface was found to be increased compared to the unmachined surface $\left(595 \mathrm{Hv}_{0.1}\right)$ for all the machining environments. The highest microhardness value $\left(700 \mathrm{Hv}_{0.1}\right)$ was observed for dry turning, whereas the lowest value $\left(625 \mathrm{Hv}_{0.1}\right)$ was obtained for Hybrid NF-MQCL. The dry environment exhibited the highest values of microhardness compared to the other cutting environments. The direct contact of tool and workpiece produces higher friction, which causes higher temperature generation and, subsequently, high flank wear. Since AISI 52100 is hard, which requires high cutting force for material removal [28], hence 


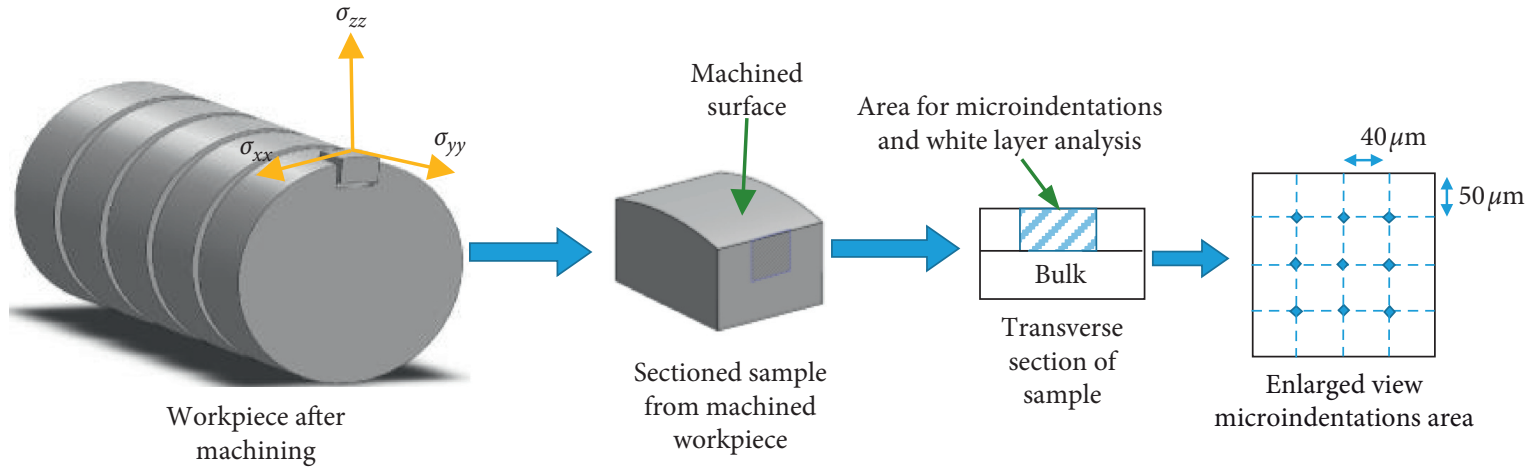

$\sigma_{x x}:$ circumferential residual stress

$\sigma_{y y}:$ axial residual stress

$\sigma_{z z}:$ radial residual stress

FIGURE 4: Sample preparation for measurement of microhardness, white layer, and residual stress.

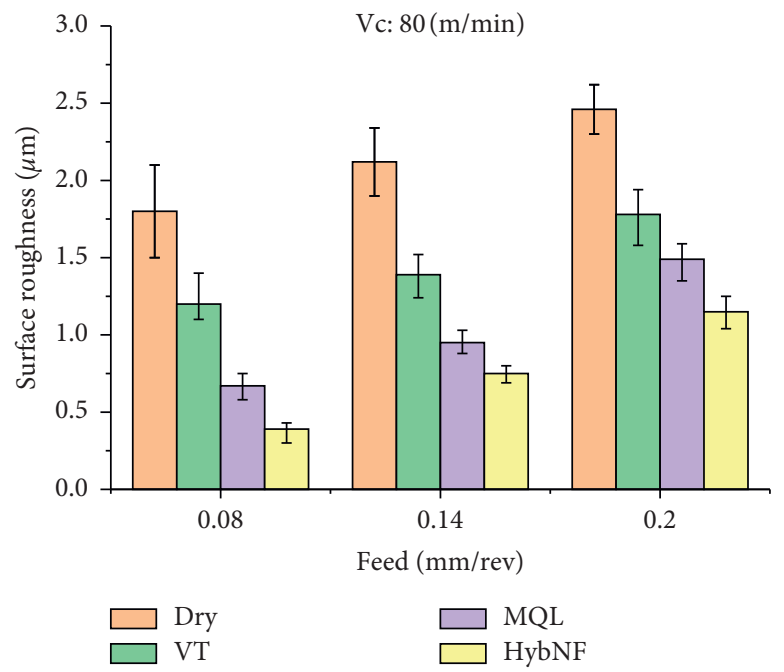

(a)

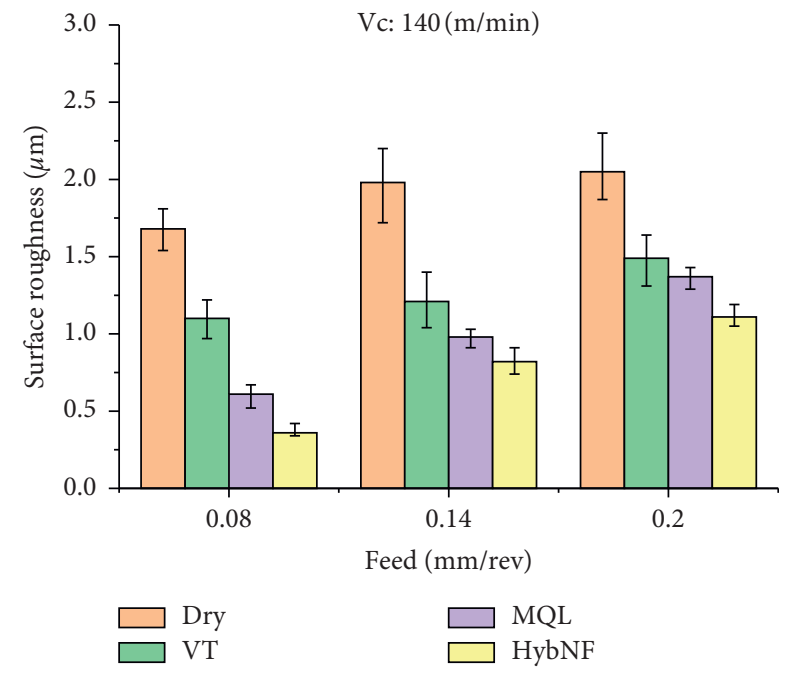

(b)

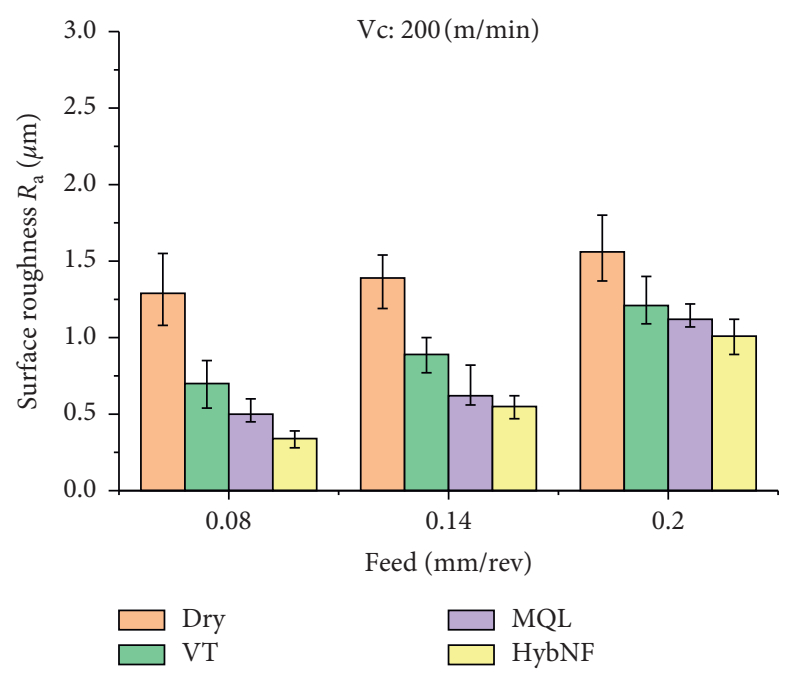

(c)

Figure 5: Effect of feed ( $\mathrm{fmm} / \mathrm{rev}$ ) on surface roughness $\left(R_{\mathrm{a}}\right)$ in near-dry machining environments at (a) $80 \mathrm{~m} / \mathrm{min}$, (b) $140 \mathrm{~m} / \mathrm{min}$, and (c) $200 \mathrm{~m} / \mathrm{min}$ cutting speeds. 


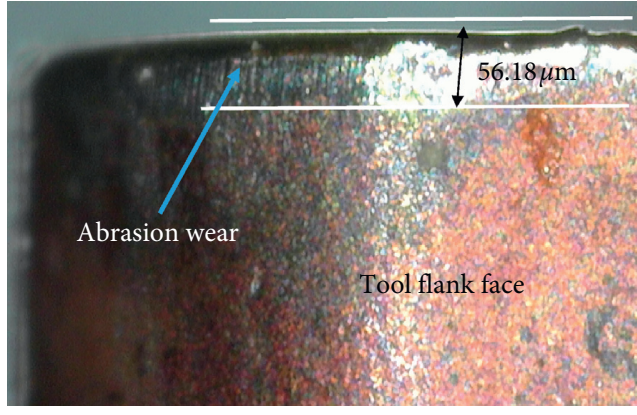

(a)

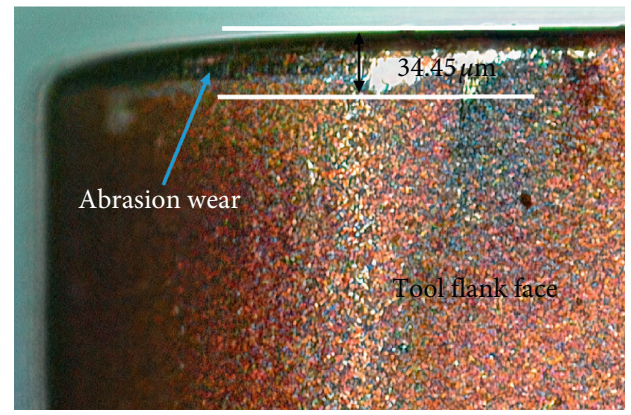

(c)

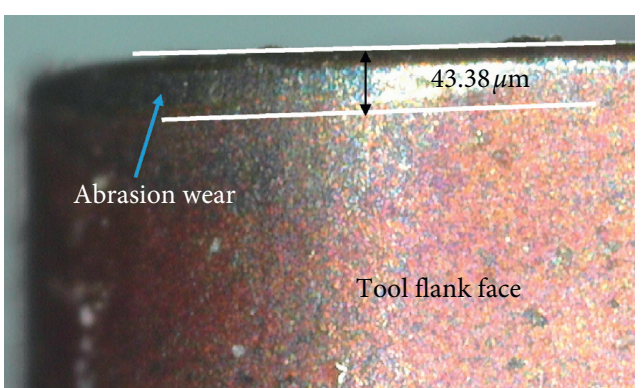

(b)

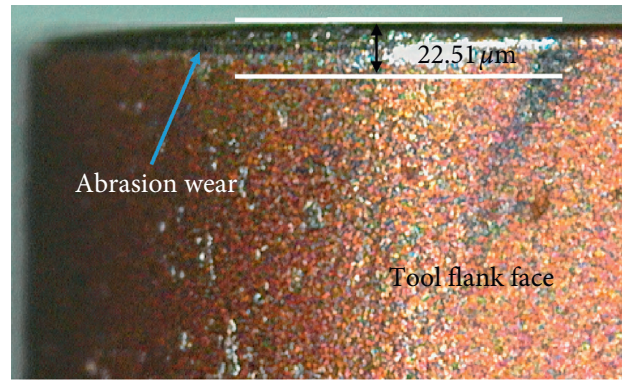

(d)

FIgure 6: Tool flank wear (after $150 \mathrm{~mm}$ ) for (a) Dry, (b) CCAVT, (c) MQCL, and (d) Hybrid NF-MQCL machining environments at Vc: $200 \mathrm{~m} / \mathrm{min}$ and $\mathrm{f}: 0.2 \mathrm{~mm} / \mathrm{rev}$.

it generates high cutting temperatures at higher cutting speed. This generated temperature reached and exceed its austenization level. The simultaneously high cooling rate occurred due to bulk material temperature difference. These phenomena are responsible for strain hardening of the machined surface [29]; therefore, it increases the hardness of the machined surface.

In the case of CCAVT, machined surface hardness was found to be lower than the dry environment. The chilled air reduces the cutting temperature in the machining zone due to forced convection mechanism [27]. The reduction in temperature slows down the austenization level of the machined surface, which may produce lowered microhardness than the dry environment. Furthermore, microhardness was found to be lower in MQCL and Hybrid NFMQCL. In MQCL, a small pressurized quantity of fluid impinges on the flank and rake face of the tool, which removes machining heat in evaporative mode [27]. This reduced cutting temperature in the machining zone lowers the austenization level temperature as well as the cooling rate of the machined surface to a notable extent. This would delay the strain hardening over the machined surface and leads to lowered microhardness. Moreover, in the case of Hybrid NF-MQCL, the lowest microhardness was observed as compared to other cutting environments. The Hybrid NFMQCL is a combination of MWCNT, $\mathrm{Al}_{2} \mathrm{O}_{3}$, and base oil. The MWCNT possesses high thermal conductivity, whereas $\mathrm{Al}_{2} \mathrm{O}_{3}$ exhibits lubrication in the tool-workpiece interface. These combined properties reduce friction and improve the cooling in the machining zone, thereby reducing the temperature generation. This significantly decreases the cooling rate in the machined surface and concurrently lessens the effect of austenization level $\left(A_{1}\right)$ of the machined surface. Substantially, it lowers the strain-hardening phenomenon over the machined surface. It causes, softens surface topography, which exhibits lowered microhardness. However, the effects of temperature and stresses were decreased with the increase in depth below the surface. Characteristically, machining zones reformed as the heat sink, due to its high heat generation. The machined surface gets affected due to localized heating and primary contact with the heat generated. With increasing depth beneath the surface, the intensity of the temperature decreases to the equilibrium temperature of bulk material, and hence it lowers microstructure alterations [30]. Therefore, microhardness was found to be reduced beneath the surface, as shown in Figure 7 . The reduction rate of microhardness beneath the surface is different in every machining environment. It is $1.83 \%$ for dry, 1.89 for CCAVT, $2.96 \%$ for MQL, and $3.1 \%$ for hybrid NF-MQCL.

3.3. Residual Stresses. The comparative effect of induced residual stresses for machined surfaces in different machining environments is shown in Figure 9, which is corroborated in Figures 10(a)-10(e). Figure 10 shows XRD plots for different machining environments. It shows $\sin ^{2} \psi$ $v s$. $d$ spacing plots, which mainly represents the correlation between surface residual stresses with $d$ spacing [31, 32]. This also represents magnitude and direction residual stresses (normal stress in the plot) for unmachined, dry, CCAVT, MQCL, and Hybrid NF-MQCL machined surface by 


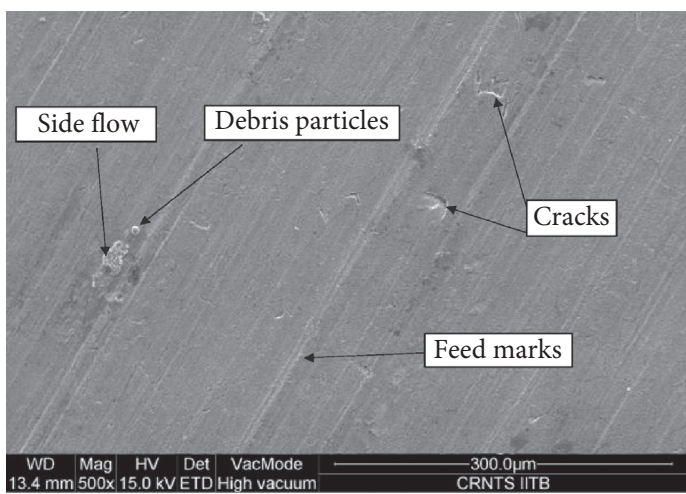

(a)

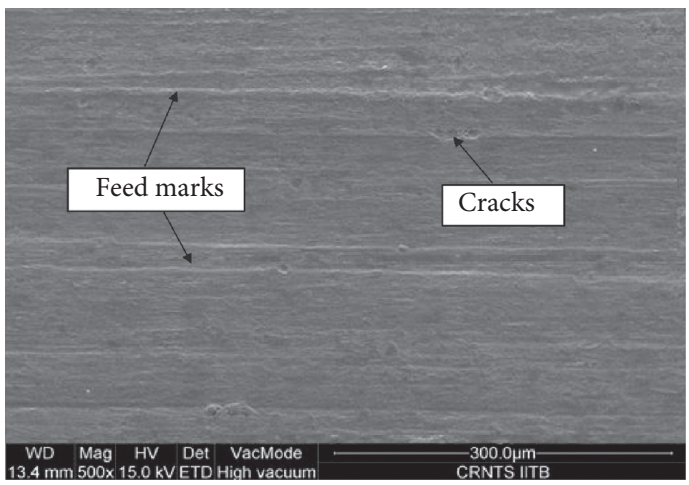

(c)

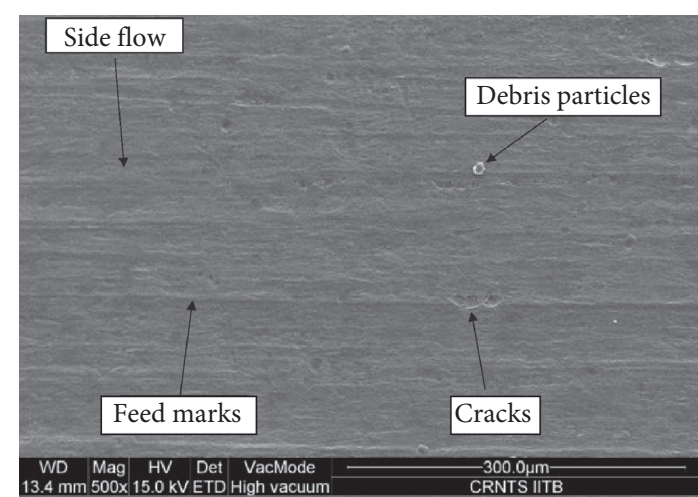

(b)

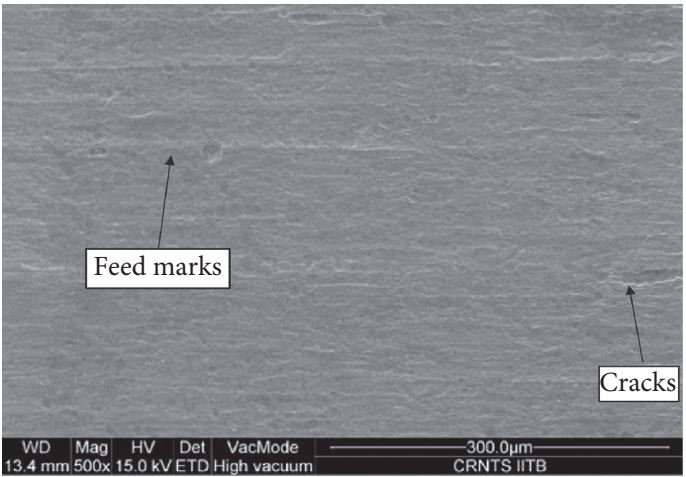

(d)

FIgure 7: Surface topography of (a) Dry, (b) CCAVT, (c) MQCL, and (d) Hybrid NF-MQCL machining environments at Vc: 200 m/min and $\mathrm{f}: 0.2 \mathrm{~mm} / \mathrm{rev}$.

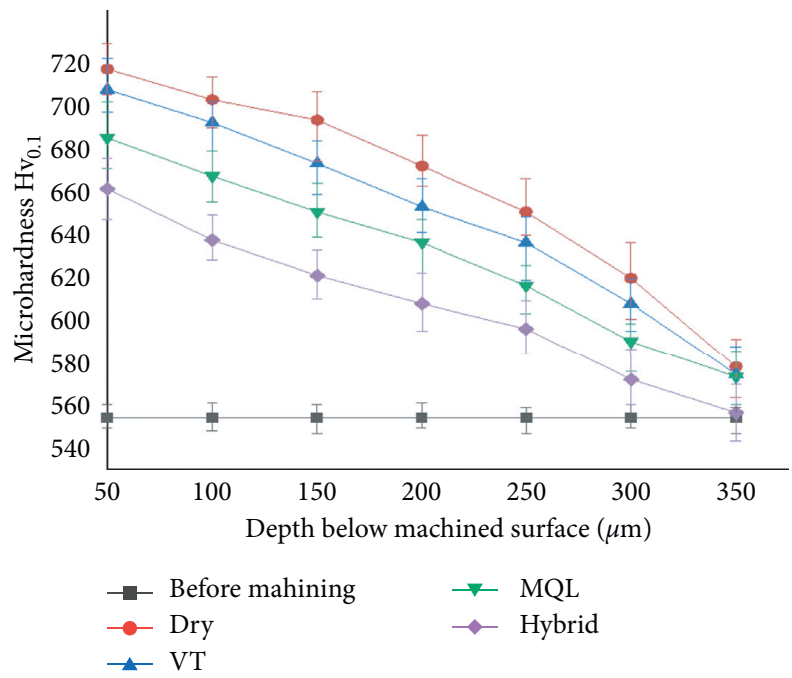

FIGURE 8: Effect of machining environment on the microhardness of machined surface of AISI 52100 steel at cutting speed, $200 \mathrm{~m} / \mathrm{min}$ and feed, $0.2 \mathrm{~mm} / \mathrm{rev}$.

Figures 10(a)-10(e), respectively. Figure 10(a) shows that the unmachined surface shows compressive stress with a magnitude of $-770 \mathrm{MPa}$. The dry machined surface exhibits the tensile residual stress of 951.7 MPa. Moreover, the surface machined under CCAVT and MQCL cutting environments show lower tensile residual stresses with a magnitude of 407 and $65.9 \mathrm{MPa}$, respectively. However, Hybrid
NF-MQCL exhibited compressive residual stress of 168.8 $\mathrm{MPa}$. From it it is clear that the different machining environment substantially affects the generation of the residual stresses over the surface. Similar results were observed in Leppert et al. and Hosseini et al. [21, 33] in hard turning of AISI 304 and AISI 52100 steel, respectively. The dry machining exhibits tensile residual stresses; it is due to the 


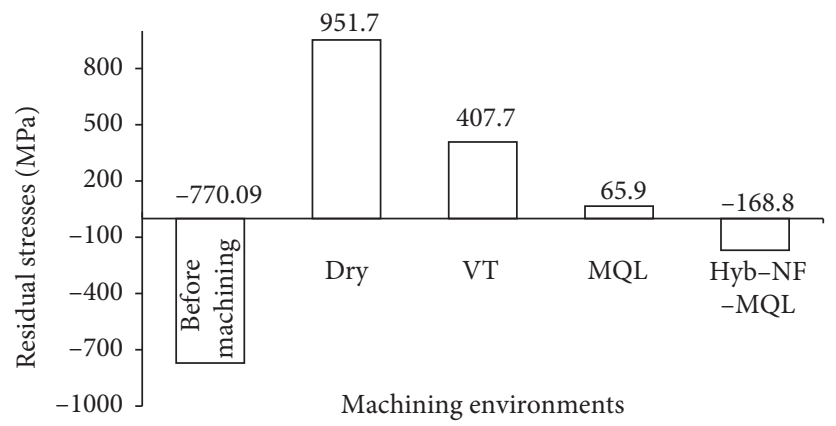

Figure 9: Effect of machining environments on residual stresses at cutting speed, $200 \mathrm{~m} / \mathrm{min}$ and feed, $0.2 \mathrm{~mm} / \mathrm{rev}$.

impartment of the strain (Figure 10(b)) because the applied mechanical forces generate mechanical stress and high temperature. Tensile residual stresses is observed due to dominant thermal effects [21]. This is due to the longer interaction distance of the tool and workpiece owing to wear, leading to higher friction, which causes more heat in the machining zone [33]. Also, higher hardness promotes the strain-hardening phenomenon [34]. This combined effect increases temperature generation in the cutting region, which results in higher tensile residual stresses. Consequently, it increases the stresses on the surface. In contrast, the Hybrid NF-MQCL environment gives lowered surface residual stresses. It is because of the excellent coolant and lubrication properties of Hybrid NF-MQCL. The presence of MWCNT removes heat significantly, and $\mathrm{Al}_{2} \mathrm{O}_{3}$ exhibits better lubrication in the tool and workpiece zone due to its low coefficient of friction $[24,35]$. This combined effect lowers the friction and temperature between tool-workpiece and tool-chip interface. It reduces the forces and stresses to be generated, which decreases the strain impartment on the surface. Therefore, it shows compressive stresses. Moreover, MQCL is more effective than CCAVT, which lowers the machining zone temperature. The MQCL produces oil film in between tool and workpiece, which reduces the temperature in the cutting zone leads to minimization tool wear. That may control heat generations in the machining zone and reduce the contact of the tool. Therefore, reduced thermal effects give a lower generation of residual stresses. Besides, CCAVT carries away generated heat continuously with the help of chilled air. This is just a sufficient method to slow down the heat generation process of the machining zone apart from controlling tool wear. Therefore, surface residual stresses were encountered to be lower than the dry machining.

3.4. White Layer Formation. Characteristically, white layers are brittle, hard, and inherently associated with tensile residual stressed untampered martensite phase transformed layer and have significance in the reduction of functional life of the machined components. Figures 11(a)-11(d) show white layer formations with their thickness for different machining environments, such a dry, CCAVT, MQCL, and Hybrid NF-MQCL, respectively. The average thickness values of the white layer were found to be 3.9, 2.5, 1.9, and $0.9 \mu \mathrm{m}$ for the order mentioned above, respectively.
Figure 11(a) clearly shows that dry machined surfaces exhibit a thickened white layer formation as compared to others. A similar range of white layer thickness is also observed by Alok and Das [36]. They measured white layer thickness near about $3 \mu \mathrm{m}$ at $\mathrm{Vc}:-220 \mathrm{~m} / \mathrm{min}, \mathrm{f}:-0.01$ and ap: $0.08 \mathrm{~mm}$. Aramcharoen and Mativenga [30] also analyzed microhardness, and the white layer thickens in hard turning of AISI H13 steel using CrTiAlN and CrTiAl+MoST coated carbide tool. At Vc: $200 \mathrm{~m} / \mathrm{min}$, ap: $0.1 \mathrm{~mm}$ and f: $0.3 \mathrm{~mm} / \mathrm{rev}$, they found $2 \mu \mathrm{m}$ thick white layer.

In dry machining, the white layer formation is associated with (i) rapid heating and quenching of the material, (ii) plastic flow (strain hardening), and (iii) surface reaction [30]. Hard turning was carried out at high speed, which is responsible for intense heat generation at the cutting zone. This workpiece material temperature in the cutting edge region exceeds the temperature of $A_{1}$ transformation. Its consequences are $\alpha-\gamma$ phase transformation energies on the surface. Subsequently, the low temperature of bulk material triggers the heat transmission from higher to lower temperature regions for the rapid cooling rate, which was sufficient for the development of the martensitic structure [29]. This leads to the initiation of the surface hardening process. Simultaneously, the contact length of tool and workpiece material (tool wear) causes undesirable friction and pressure that could be attributed to the high friction coefficient $[33,37]$. This may produce high mechanical cutting forces in the surface layer causing high tool-workpiece contact temperature. This incites the strain hardening process in the surface layers; it imparts strain in the machined surface. Besides, carbide coated tools diffuse the carbon content to the machined layer. The generated $A_{1}$ transformation temperature is just sufficient to trigger the carbon diffusion process. It possibly deposits and embeds a carbon-rich cluster over the machined surface. The carbides over in the machined surface layer may create a hardened structure, which significantly increases the hardness of the surface layer [38]. Concurrently, in the machining zone, rapid heating and quenching occurred due to different temperatures between the machined surface and bulk material, which results in martensitic structure formation [39]. These cumulative mechanisms cause the microstructure alterations by martensitic phase transformation. All these phenomena lead to the formation of fine martensitic structure, which turns into a white layer. 

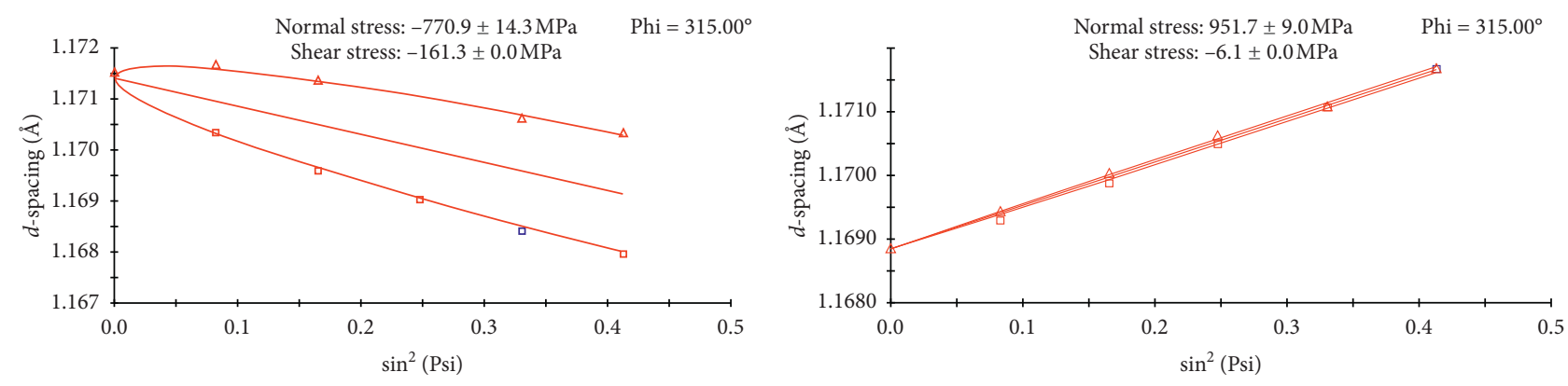
$\triangle \mathrm{Psi} \geq 0$
$\triangle \mathrm{Psi} \geq 0$
$\square \mathrm{Psi}<0$

(a)
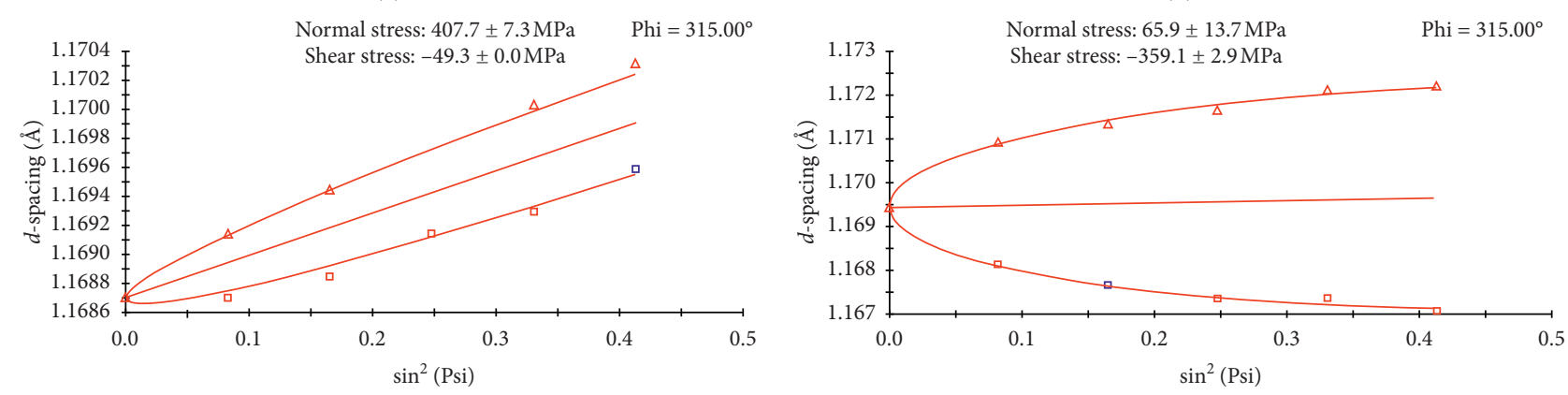

$\triangle \mathrm{Psi} \geq 0$
$\square \quad \mathrm{Psi}<0$

$\triangle \mathrm{Psi} \geq 0$

$\square$ Psi $<0$

(c)

(d)

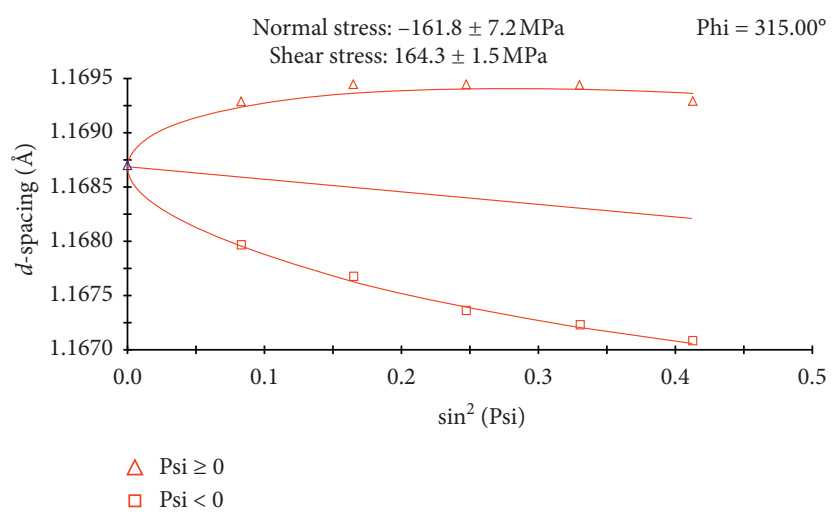

(e)

FIGURE 10: XRD Analysis using $d$-spacing vs. $\sin ^{2} \psi$ plots for all near-dry machining environments at Vc: $200 \mathrm{~m} / \mathrm{min}$ and f: $0.2 \mathrm{~mm} / \mathrm{rev}$. (a) Before machining; (b) dry machining environment; (c) CCAVT machining environment; (d) MQCL machining environment; (e) Hybrid NF-MQCL machining environments.

However, Figures 11(b) and 11(c) show $2.5 \mu \mathrm{m}$ and $1.9 \mu \mathrm{m}$ thick white layer under CCAVT and MQCL machining environments, respectively. As noted, high machining temperature is responsible for white layer formation. The application of these environments, such as CCAVT, carried away generated heat by chilled air, whereas MQCL effectively and efficiently lowers heat generation from the machining zone. These processes exhibit their competency by lessening the heat effect on the machined surface. This lower impact of temperature and, therefore, the reduced white layer were observed. Contradictorily, HybNF-MQCL shows a significant reduction in white layer thickness to $0.9 \mu \mathrm{m}$, as shown in Figure 11(d). The mixture of MWCNT and $\mathrm{Al}_{2} \mathrm{O}_{3}$ nanoparticles in base oil effectively lowers heat generation in the machining zone and reduces the friction phenomenon in between chip-tool interaction. The MWCNT poses with good heat conductivity, carrying away generated heat from the machining zone, whereas $\mathrm{Al}_{2} \mathrm{O}_{3}$ works excellent solid lubricant by reducing the frictional phenomenon. This combined effect lessens the generated heat intensity of the machining zone, which does not pose the austenization level $\left(\mathrm{A}_{1}\right)$ temperature. Hence, the temperature difference between the worked surface and bulk material is lower, which reduces the cooling rate due to 


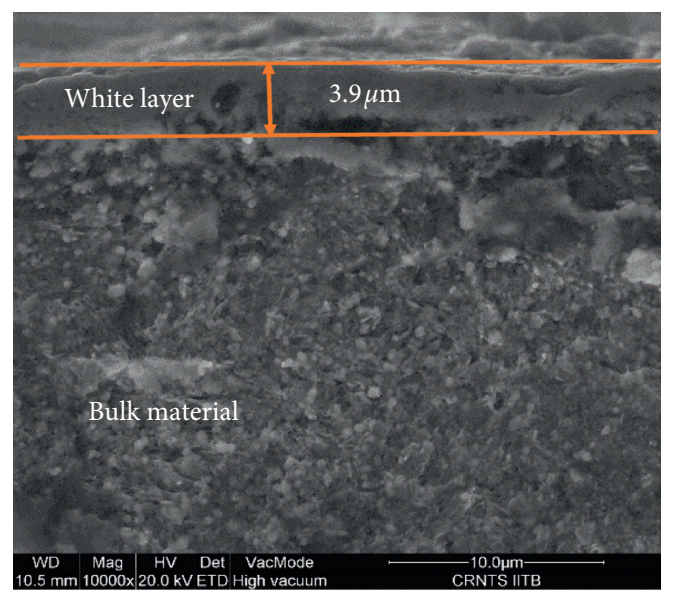

(a)

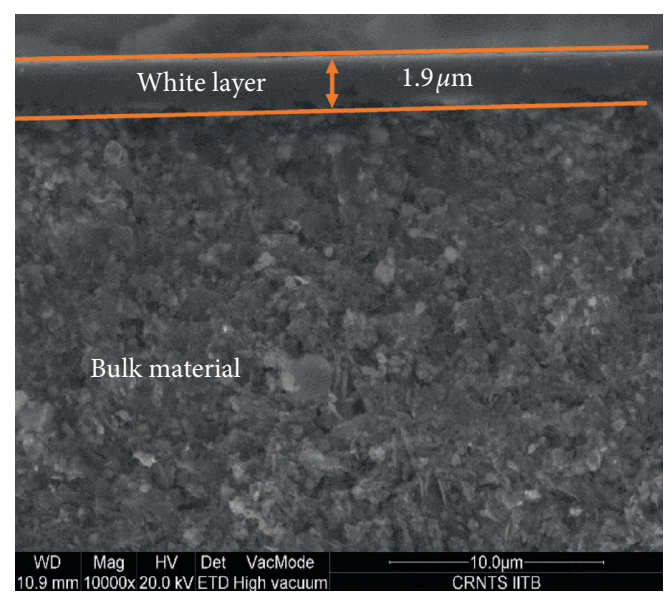

(c)

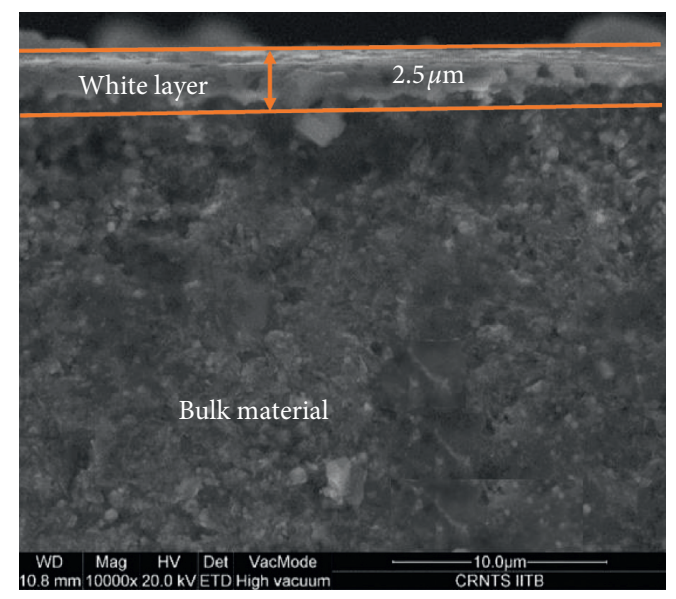

(b)

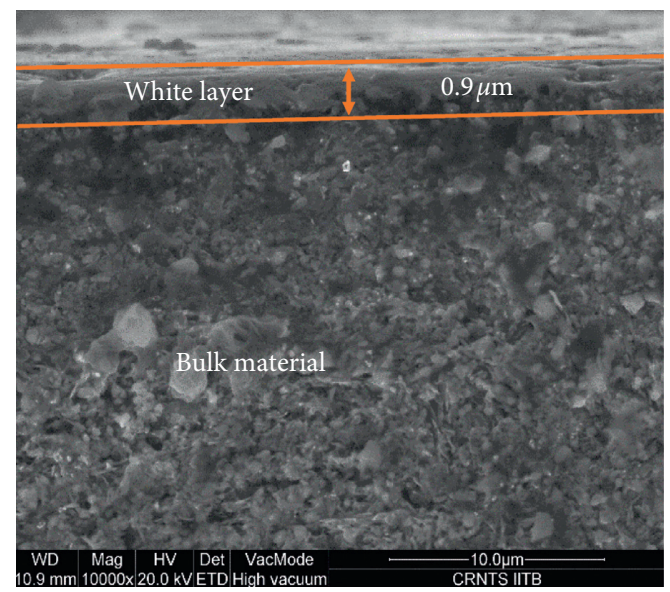

(d)

FIGURE 11: SEM images of white layer for different near-dry machining environments at cutting speed, $200 \mathrm{~m} / \mathrm{min}$ and feed, $0.2 \mathrm{~mm} / \mathrm{rev}$. (a) Dry environment; (b) CCAVT environment; (c) MQCL environment; (d) Hybrid NF-MQCL environment.

insufficient rapid heating and quenching of the material. Concurrently, lowered strain hardening, and surface reactions were observed. This ultimately leads to a reduction in white layer formation.

\section{Conclusions}

In this study, the following conclusions are drawn:

(1) Different machining environments influence the surface integrity of AISI52100 steel in hard turning. The Hybrid NF-MQCL showed better surfacequality as compared to other near-dry cutting environments.

(2) The highest $R_{\mathrm{a}}$ value, $1.8 \mu \mathrm{m}$, was obtained in dry, whereas the lowest value of $0.34 \mu \mathrm{m}$ was obtained for Hybrid NF-MQCL. The results show that $R_{\mathrm{a}}$ values were found to be improved by $34 \%$ for Hybrid NFMQCL, 26\% for MQL, and 20\% for CCAVT as compared to dry machining environments. This is because of the high friction and tool wear observed in dry environments, whereas Hybrid NF-MQCL was associated with low friction and tool wear.
(3) It is found that microhardness of the machined surface and subsurface was increased. Hybrid NFMQCL exhibited $8.5 \%$ reduction in the microhardness $\left(625 \mathrm{Hv}_{0.1}\right)$ compared to the dry machined surface. The CCAVT and MQCL showed 3\% and 5\% reduction in the microhardness as compared to dry. It is due to the cooling and lubrication effect on the cutting zone, which influences the machining temperature and strain-hardening rate.

(4) Hybrid NF-MQCL lower compressive residual stresses in the machined surface, whereas the dry machining environment imparts high tensile residual stresses. CCAVT and MQL machining environments produce $58 \%$ and $93 \%$ less tensile residual stresses as compared to dry machining environment. This is because of the high temperature, and plastic deformation gives the strain in the atomic structure. In contrast, Hybrid NF-MQCL possesses low cutting temperature and plastic deformation, that is, lower residual stresses.

(5) The high white layer thickness was obtained for dry environment whereas low for Hybrid NF-MQCL. 
Hybrid NF-MQCL lowers the tool wear, which reduces the temperature and friction in the cutting zone, and hence a thin white layer is obtained. The dry machined surface shows a thicker white layer due to low cooling and lubrication, whereas Hybrid NFMQCL lowers the tool wear, which reduces the temperature and friction in cutting zone and hence the thin white layer.

\section{Data Availability}

The data of this study can be available from the corresponding author upon request.

\section{Additional Points}

The study is not considered parametric analysis which may be a future scope.

\section{Conflicts of Interest}

The authors declare no conflicts of interest.

\section{Acknowledgments}

The MHRD of India supported this work through the TEQIP II program of the World Bank.

\section{References}

[1] C. M. Allen and B. Boardman, "ASM handbook, volume 1, properties and selection: irons, steels, and high performance alloys section: publication information and contributors publication information and contributors," Fonderie, vol. 1, p. 1618, 2005.

[2] S. Chinchanikar and S. K. Choudhury, "Machining of hardened steel-experimental investigations, performance modeling and cooling techniques: a review," International Journal of Machine Tools and Manufacture, vol. 89, pp. 95109, 2015.

[3] S. K. Shihab, Z. A. Khan, A. Mohammad, and A. N. Siddiquee, "A review of turning of hard steels used in bearing and automotive applications," Production \& Manufacturing Research, vol. 2, no. 1, pp. 24-49, 2014.

[4] S. Saini, I. S. Ahuja, and V. S. Sharma, "Residual stresses, surface roughness, and tool wear in hard turning: a comprehensive review," Materials and Manufacturing Processes, vol. 27, no. 6, pp. 583-598, 2012.

[5] R. Suresh, S. Basavarajappa, V. N. Gaitonde, G. Samuel, and J. P. Davim, "State-of-the-art research in machinability of hardened steels," Proceedings of the Institution of Mechanical Engineers, Part B: Journal of Engineering Manufacture, vol. 227, no. 2, pp. 191-209, 2013.

[6] J. Paulo Davim, Surface Integrity in Machining, Springer, London, UK, 2010.

[7] F.-y. Zhang, C.-z. Duan, M.-j. Wang, and W. Sun, "White and dark layer formation mechanism in hard cutting of AISI52100 steel," Journal of Manufacturing Processes, vol. 32, pp. 878887, 2018.

[8] F. Zhang, C. Duan, W. Sun, and K. Ju, "Effects of cutting conditions on the microstructure and residual stress of white and dark layers in cutting hardened steel," Journal of Materials Processing Technology, vol. 266, pp. 599-611, 2019.
[9] R. G. Chaudhari and F. Hashimoto, "Process controls for surface integrity generated by hard turning," Procedia CIRP, vol. 45, pp. 15-18, 2016.

[10] W. Jomaa, V. Songmene, and P. Bocher, "An investigation of machining-induced residual stresses and microstructure of induction-hardened AISI 4340 steel," Materials and Manufacturing Processes, vol. 31, no. 7, pp. 838-844, 2016.

[11] R. Kumar, A. K. Sahoo, P. C. Mishra, and R. K. Das, "Comparative investigation towards machinability improvement in hard turning using coated and uncoated carbide inserts: part I experimental investigation," Advances in Manufacturing, vol. 6, no. 1, pp. 52-70, 2018.

[12] A. K. Sahoo, "Application of Taguchi and regression analysis on surface roughness in machining hardened AISI D2 steel," International Journal of Industrial Engineering Computations, vol. 5, no. 2, pp. 295-304, 2014.

[13] A. K. Sahoo, K. Orra, and B. C. Routra, "Application of response surface methodology on investigating flank wear in machining hardened steel using PVD TiN coated mixed ceramic insert," International Journal of Industrial Engineering Computations, vol. 4, no. 4, pp. 469-478, 2013.

[14] A. Panda, A. K. Sahoo, I. Panigrahi, and A. K. Rout, "Investigating machinability in hard turning of AISI 52100 bearing steel through performance measurement: QR, ANN and GRA study A," International Journal of Automotive and Mechanical Engineering, vol. 15, no. 1, pp. 4935-4961, 2018.

[15] A. K. Sharma, A. K. Tiwari, and A. R. Dixit, "Progress of nanofluid application in machining: a review," Materials and Manufacturing Processes, vol. 30, no. 7, pp. 813-828, 2015.

[16] V. S. Sharma, M. Dogra, and N. M. Suri, "Cooling techniques for improved productivity in turning," International Journal of Machine Tools and Manufacture, vol. 49, no. 6, pp. 435-453, 2009.

[17] M. Biček, F. Dumont, C. Courbon, F. Pušavec, J. Rech, and J. Kopač, "Cryogenic machining as an alternative turning process of normalized and hardened AISI 52100 bearing steel," Journal of Materials Processing Technology, vol. 212, no. 12, pp. 2609-2618, 2012.

[18] D. Umbrello, F. Micari, and I. S. Jawahir, "The effects of cryogenic cooling on surface integrity in hard machining: a comparison with dry machining," CIRP Annals, vol. 61, no. 1, pp. 103-106, 2012.

[19] B. Sredanović and G. Globočki Lakić, "Hard turning of bearing steel AISI 52100 with carbide tool and high pressure coolant supply," Journal of the Brazilian Society of Mechanical Sciences and Engineering, vol. 39, no. 11, pp. 4623-4632, 2017.

[20] S. Chinchanikar, A. V. Salve, P. Netake, A. More, S. Kendre, and R. Kumar, "Comparative evaluations of surface roughness during hard turning under dry and with water-based and vegetable oil-based cutting fluids," Procedia Materials Science, vol. 5, pp. 1966-1975, 2014.

[21] T. Leppert and R. L. Peng, "Residual stresses in surface layer after dry and MQL turning of AISI 316L steel," Production Engineering, vol. 6, no. 4-5, pp. 367-374, 2012.

[22] X. Bai, C. Li, L. Dong, and Q. Yin, "Experimental evaluation of the lubrication performances of different nanofluids for minimum quantity lubrication (MQL) in milling Ti-6Al-4V," The International Journal of Advanced Manufacturing Technology, vol. 101, no. 9-12, pp. 2621-2632, 2019.

[23] S. Paul, A. K. Singh, and A. Ghosh, "Grinding of Ti-6Al-4V under small quantity cooling lubrication environment using alumina and MWCNT nanofluids," Materials and Manufacturing Processes, vol. 32, no. 6, pp. 608-615, 2017. 
[24] A. Kumar Sharma, A. Kumar Tiwari, A. Rai Dixit, and R. Kumar Singh, "Measurement of machining forces and surface roughness in turning of AISI 304 steel using aluminaMWCNT hybrid nanoparticles enriched cutting fluid," Measurement, vol. 150, Article ID 107078, 2020.

[25] F. Rabiei, A. R. Rahimi, and M. J. Hadad, "Performance improvement of eco-friendly MQL technique by using hybrid nanofluid and ultrasonic-assisted grinding," The International Journal of Advanced Manufacturing Technology, vol. 93, no. 14, pp. 1001-1015, 2017.

[26] A. K. Sharma, A. K. Tiwari, A. R. Dixit, R. K. Singh, and M. Singh, "Novel uses of alumina/graphene hybrid nanoparticle additives for improved tribological properties of lubricant in turning operation," Tribology International, vol. 119, pp. 99-111, 2018.

[27] M. K. Gupta, M. Mia, G. Singh, D. Y. Pimenov, M. Sarikaya, and V. S. Sharma, "Hybrid cooling-lubrication strategies to improve surface topography and tool wear in sustainable turning of Al 7075-T6 alloy," The International Journal of Advanced Manufacturing Technology, vol. 101, no. 1-4, pp. 55-69, 2019.

[28] G. Bartarya and S. K. Choudhury, "State of the art in hard turning," International Journal of Machine Tools and Manufacture, vol. 53, no. 1, pp. 1-14, 2012.

[29] J. Kundrak, A. G. Mamalis, K. Gyani, and V. Bana, "Surface layer microhardness changes with high-speed turning of hardened steels," The International Journal of Advanced Manufacturing Technology, vol. 53, no. 1-4, pp. 105-112, 2011.

[30] A. Aramcharoen and P. T. Mativenga, "White layer formation and hardening effects in hard turning of H13 tool steel with CrTiAlN and CrTiAlN/MoST-coated carbide tools," The International Journal of Advanced Manufacturing Technology, vol. 36, no. 7-8, pp. 650-657, 2008.

[31] S. B. Thorat and S. Mudigonda, "The relative influence of surface metallurgy and self-magnetization induced by different manufacturing processes on surface integrity of Co-Cr alloy using PCM," Materials Characterization, vol. 167, Article ID 110526, 2020.

[32] S. Thorat and M. Sadaiah, "Investigation on surface integrity of Co-Cr L605 alloy in photochemical machining," Journal of Manufacturing Processes, vol. 38, pp. 483-493, 2019.

[33] S. B. Hosseini, K. Ryttberg, J. Kaminski, and U. Klement, "Characterization of the surface integrity induced by hard turning of bainitic and martensitic AISI 52100 steel," Procedia CIRP, vol. 1, no. 1, pp. 494-499, 2012.

[34] S. Thorat and M. Sadaiah, "The effect of residual stresses, grain size, grain orientation, and hardness on the surface quality of Co-Cr L605 alloy in Photochemical Machining," Journal of Alloys and Compounds, vol. 804, pp. 84-92, 2019.

[35] M. Jamil, A. M. Khan, H. Hegab et al., "Effects of hybrid $\mathrm{Al}_{2} \mathrm{O}_{3}$-CNT nanofluids and cryogenic cooling on machining of Ti-6Al-4V," The International Journal of Advanced Manufacturing Technology, vol. 102, no. 9-12, pp. 3895-3909, 2019.

[36] A. Alok and M. Das, "White layer analysis of hard turned AISI 52100 steel with the fresh tip of newly developed HSN2 coated insert," Journal of Manufacturing Processes, vol. 46, pp. 16-25, 2019.

[37] S. Zhang, J. Li, and H. Lv, "Tool wear and formation mechanism of white layer when hard milling H13 steel under different cooling/lubrication conditions," Advances in Mechanical Engineering, vol. 2014, Article ID 949308, 2014.

[38] S. B. Hosseini, M. Thuvander, U. Klement, G. Sundell, and K. Ryttberg, "Atomic-scale investigation of carbon atom migration in surface induced white layers in high-carbon medium chromium (AISI 52100) bearing steel," Acta Materialia, vol. 130, pp. 155-163, 2017.

[39] D. Umbrello, "Influence of material microstructure changes on surface integrity in hard machining of AISI 52100 steel," The International Journal of Advanced Manufacturing Technology, vol. 54, no. 9-12, pp. 887-898, 2011. 